[4] Heidari B, Hassanjani Roushan MR. Rheumatoid arthritis and osteoporosis. Caspian J Intern Med. 2012;3(3):445-6.

[5] Sözen T, Özışık L, Başaran NÇ. An overview and management of osteoporosis. Eur J Rheumatol. 2016;4(1):46-56

Disclosure of Interests: None declared

DOI: 10.1136/annrheumdis-2019-eular.2203

\section{AB0839 ASSOCIATION BETWEEN BODY FAT AND BONE MINERAL DENSITY IN POSTMENOPAUSAL WOMEN THROUGH RADIOFREQUENCY ECHOGRAPHIC MULT SPECTROMETRY}

Elena Kirilova ${ }^{1}$, Nikola Kirilov ${ }^{2}$, Stoyanka Vladeva ${ }^{1} .{ }^{1}$ Trakia university, Stara Zagora, Bulgaria; ${ }^{2}$ Medical University of Sofia, Stara Zagora, Bulgaria

Background: Osteoporosis is characterized by reduced bone mineral density (BMD) and increased fracture risk. Age, concomitant diseases, body mass index (BMI), body composition, etc. are important risk factors that could reflect on bone density and on the increased risk of fractures. Although obesity has been associated with increased bone mineral density (BMD) in the most studies, the relationship between body fat and $\mathrm{BMD}$ remains contradictive.

Objectives: The aim of this study is to determine if there is any association between body fat distribution and bone mineral density in postmenopausal women through novel ultrasound technique applicable on bothlumbar spine and femoral neck.

Methods: A total of 98 women with mean age $62 \pm 11$ years underwent radiofrequency echographic multi spectrometry (REMS). Bioelectrical impedance analysis (BIA) software was used to assess body fat percentage. Patients were divided into two groups-with body fat $>32 \%$ and body fat $<32 \%$. Age, BMI, lumbar spine BMD, total hip BMD and fracture risk score (FRAX) were compared between the patients with normal body fat and those with high body fat.

Results: The mean age of the women with normal body fat was 61.1 \pm 14.6 years and the mean age of the women with high body fat was $63.3 \pm 9.5$ years. BMI of the women with body fat $<32 \%$ was significantly lower $\left(22.5 \mathrm{~kg} / \mathrm{cm}^{2}\right)$ compared to the BMl of the women with body fat $\geq$ $32 \%\left(30.2 \mathrm{~kg} / \mathrm{cm}^{2}\right)(p=0.000)$. Bone mineral density of L1-L4 and tota lumbar spine BMD did not differ between the women with normal body fat and high body fat. Femoral neck BMD, trochanteric BMD and total hip BMD of the patients with normal body fat $\left(0.604 \mathrm{~g} / \mathrm{cm}^{2}, 0.737 \mathrm{~g} / \mathrm{cm}^{2}\right.$ and $0.736 \mathrm{~g} / \mathrm{cm}^{2}$ respectively) were significantly lower than those patients with high body fat $\left(0.682 \mathrm{~g} / \mathrm{cm}^{2}, 0.864 \mathrm{~g} / \mathrm{cm}^{2}\right.$ and $0.838 \mathrm{~g} / \mathrm{cm}^{2}$ respectively) ( $p=0.000$ for femoral neck $B M D$ and trochanteric $B M D$, and $p=$ 0.001 for total hip BMD). FRAX score for 10 -year probability of major osteoporotic fracture did not differ significantly between the two groups (20.8\% for women with normal body fat and $16.6 \%$ for women with high body fat). FRAX score for 10-year probability of hip fracture was also not significant between the two groups, but there was a trend to statistical significance $(p=0.059)$ ( $9 \%$ for women with normal fat and $4.9 \%$ for women with high fat)

Conclusion: Postmenopausal women with body fat $>32 \%$ showed higher femoral neck BMD compared to those with body fat $<32 \%$, but there was no significant difference in the lumbar spine BMD values between the groups. Women with high body fat did not show significantly lower FRAX score than the women with normal body fat.

\section{REFERENCES}

11] Paola Pisani, Francesco Conversano, FernandaChiriacò, Eugenio Quarta, Laura Quarta, MaurizioMuratore, Aimè Lay-Ekuakille, Sergio Casciaro. Estimation of femoral neck bone mineral density by ultrasound scanning: Preliminary results and feasibility. Measurement, Volume 94, 2016, pp. 480-486

[2] Shapses SA, Sukumar D. Bone metabolism in obesity and weight loss. Annu Rev Nutr. 2012;32:287-309.

[3] SILVA, Ana Carolina Veiga, et al. Factors associated with osteopenia and osteoporosis in women undergoing bone mineral density test. Rev. Bras. Reumatol. [online]. 2015, vol.55

[4] Zhao LJ, Jiang H, Papasian CJ, et al. Correlation of obesity and osteoporosis: effect of fat mass on the determination of osteoporosis. $J$ Bone Miner Res. 2007;23(1):17-29.

\section{$\mathrm{AB} 0840$}

SCREENING FOR OSTEOPOROSIS IN AN AMBULATORY AND HOSPITALIZED POPULATION: A 6YEAR EXPERIENCE IN A UNIVERSITY HOSPITAL

Olivier Malaise ${ }^{1}$, Marie Detroz ${ }^{1}$, Mathieu Leroy ${ }^{1}$, Lorenzo Leonori ${ }^{1}$, Laurence Seidel ${ }^{2}$, Michel Malaise ${ }^{1} .{ }^{1}$ Chu De Liège, Department of Rheumatology, Liège, Belgium; ${ }^{2}$ Chu De Liège, Department of Biostatistics, Liège, Belgium

Background: Osteoporosis (OP) is a serious and prevalent disease identified by Dual Energy X-ray Absorptiometry (DEXA) that can be performed in an ambulatory or an hospitalized population.

Objectives: Aims are: (1) to characterize patients who had DEXA in a university department of rheumatology to study its diagnostic efficacy; (2) to look after risk factors specific to our population; (3) to evaluate the efficiency of a non-systematic and opportunistic intra-hospital OP screening by comparing results for ambulatory and hospitalized patients in the different departments of the hospital.

Methods: From 2007 to 2012, 6406 initial DEXA from consecutive patients were prospectively encoded (1494 in 2007, 1158 in 2008, 1079 in 2009, 945 in 2010, 868 in 2011 and 862 in 2012) (identical DEXA). Results: Cohort characteristics are the following: women $74.4 \%$, mean age ( \pm 1 standard deviation) 60.5 years $( \pm 14.3)$, mean BMI 25.1 ( \pm 5.1 , history of corticotherapy in $30.5 \%$, previous fracture in $29 \%$ and current hospitalization in $28.8 \%$ of cases. OP (at one of the 3 sites) was diagnosed in $22.3 \%$, a stable value over the years, with, as a repartition, lumbar spine, femoral neck and total hip OP in $13.7 \%, 13.6 \%$ and $9.2 \%$ respectively. In $3.9 \%$, OP was diagnosed at all the 3 sites. In univariate analysis, OP risk factors were age, history of fracture and low BMI (for all 3 sites), corticotherapy (lumbar spine and femoral neck) and male gender (lumbar spine). In multivariate analysis, regardless of site, age, fracture history, low BMI, and male gender increased the OP risk. Intra-hospital screening identified OP (at any of the 3 sites) in $31.8 \%$ (vs $18.5 \%, p<0.001$ for ambulatory screening) and OP at 3 sites simultaneously in $7.9 \%$ (vs $2.3 \%, p<0.0001$ ). This better efficiency was stable and present for each year analyzed. The intra-hospital population tested was older [64.2 years (13.2) vs 59 (13.2), $\mathrm{p}<0.0001$ ], with more men $(35.2 \%$ vs $21.7, \quad p<0.0001)$, more history of fracture $(39 \%$ vs 24 $\mathrm{p}<0.0001)$ and with a slightly higher BMI $[25.4$ (5.8) vs 25.1 (4.8), $\mathrm{p}=0.028$ ], with no difference in corticosteroid use. In addition to T-scores analyzes, Z-scores were also compared and showed similar differences with lower Z-scores in the hospitalized population.

Conclusion:

(1) One in five DEXA identified OP at one of the three sites in the ambulatory population but only one in three in the hospitalized patients. Hospital screening is therefore essential and more efficient than the ambulatory one. Hospital time seems to be an opportunity to fill the gaps in ambulatory screening.

(2) Intra-hospital screening targeted an older and more masculine population with more fracture history, which may explain its better performance, which does not decline over the years. Z-score differences revealed that the efficiency difference was not only due to an older age of the hospitalized population but could be secondary to more internistical co-morbidities or treatment deleterious for bones.

(3) In addition to conventional ones, the male gender is a risk factor for OP recalling the importance of screening for all and not only in the female population (which represents $3 / 4$ of the cohort).

Disclosure of Interests: Olivier Malaise Speakers bureau: Amgen, Marie Detroz: None declared, Mathieu Leroy: None declared, Lorenzo Leonori: None declared, Laurence Seidel: None declared, Michel Malaise: None declared

DOI: 10.1136/annrheumdis-2019-eular.422

\section{$\mathrm{AB} 0841$ PROSPECTIVE STUDY OF BONE METABOLISM AND FRACTURE INCIDENCE IN SPINAL CORD INJURY PATIENTS DURING A PERIOD OF 24 MONTHS}

Isabel Martínez Cordellat ${ }^{1}$, Jose Ivorra Cortés ${ }^{1}$, Fátima Torralba Collados ${ }^{2}$ Carmen Grao Castellote ${ }^{2}$, Cristina Alcañiz Escandell, Inmaculada Chalmeta Verdejo ${ }^{1}$, Marta De la Rubia Navarro ${ }^{1}$, Jorge Juan Fragio-Gil ${ }^{1}$, Roxana Gonzalez Mazario $^{1}$, Luis Gonzalez Puig ${ }^{1}$, Elena Grau García ${ }^{1}$, Rosa Negueroles Albuixech ${ }^{1}$, Jose Eloy Oller Rodríguez ${ }^{1}$, Francisco Miguel Ortiz Sanjuan ${ }^{1}$, Cristobal Pávez Perales ${ }^{1}$, Elvira Vicens Bernabeu ${ }^{1}$, Carmen Nájera Herranz ${ }^{1}$, Inés Cánovas Olmos ${ }^{1}$, Jose Andrés Román Ivorra ${ }^{1}$.

${ }^{1}$ Rheumatology Department. HUP La Fe, Valencia, Spain; ${ }^{2}$ Spinal Cord Injury Unit. HUP La Fe, Valencia, Spain

Background: Spinal Cord Injury (SCl) produces a wide variety of changes in systemic physiology that can lead to several complications, 
such as Osteopenia or even Osteoporosis. It has been reported in several studies, an incidence of fracture between $30-40 \%$ in this population. Objectives: To evaluate the evolution of bone turnover biomarkers before and after treatment (according to 2015 NOF guidelines) and to describe the incidence of fracture after a SCl.

Methods: A prospective study was conducted, including $48 \mathrm{SCl}$ patients followed during an observation period of 24 months, with visits every six months. Thirty two patients concluded the study. In each visit patients were enquired about fractures. A blood test was also performed. In addition a dual-energy x-ray absorptiometry (DEXA) and simple x-ray of hip and spine was requested annually. Patients were also educated in lifestyle measures, such as an adequate calcium and vitamin D dietary intake. Oral supplementation was initiated in cases of low intake or deficit, respectively. In patients with bone mineral density (BMD) measured by DEXA in range of Osteoporosis, pharmacological therapy was initiated (bisphosphonate or Denosumab). Statistics had been performed with mixed linear regression models.

Results: Our sample was $56.25 \%$ men with an average age of $56.08 \pm$ 13.82 years old. In 32 patients $(68.09 \%)$ low Vitamin D levels were detected. At baseline in 12 cases (25\%) DEXA showed a BMD in osteoporosis range; in $12(25 \%)$ osteopenia, plus 6 fractures (2.6 fractures per 100 years/patient). Afterwards, until the end of the study only a fracture of the tibia was observed (however, it was after a high impact accident), so the fracture rate was 1.2 fractures per 100 year/patient.

The evolution of the variables can be seen on the next table.

\begin{tabular}{lccccc}
\hline & $\begin{array}{c}\text { Month-0 } \\
\mathbf{N}=\mathbf{4 8}\end{array}$ & $\begin{array}{c}\text { Month-6 } \\
\mathbf{N = 3 2}\end{array}$ & $\begin{array}{c}\text { Month-12 } \\
\mathbf{N = 3 6}\end{array}$ & $\begin{array}{c}\text { Month-18 } \\
\mathbf{N = 3 7}\end{array}$ & $\begin{array}{c}\text { Month 24 } \\
\mathbf{N = 3 2}\end{array}$ \\
& Mean (SD) & Mean (SD) & Mean (SD) & Mean (SD) & Mean (SD) \\
\hline CALCIUM (mg/dl) & $9.1(0.59)$ & $9.53(0.4)$ & $9.37(0.54)$ & $9.46(0.41)$ & $9.55(0.44)$ \\
PHOSPHOR (mg/dl) & $3.63(0.7)$ & $3.42(0.44)$ & $3.32(0.52)$ & $3.33(0.55)$ & $3.25(0.45)$ \\
VIT D (UI) & 16.42 & 42.28 & 35.88 & 35.77 & 37.55 \\
& $(9.95)$ & $(18.93)$ & $(13.53)$ & $(18.08)$ & $(15.06)$ \\
PTH (ng/mL) & 38.15 & 36.09 & 38.33 & 40.1 & 43.35 \\
& $(25.55)$ & $(17.89)$ & $(21.2)$ & $(17.27)$ & $(25.08)$ \\
PINP (ng/mL) & 79.25 & 68.15 & 53.05 & 42.82 & 40.67 \\
& $(80.9)$ & $(35.77)$ & $(45.76)$ & $(24.26)$ & $(25.17)$ \\
bCTX (ng/mL) & $0.82(0.49)$ & $1.23(4.22)$ & $0.34(0.35)$ & $0.28(0.21)$ & $0.51(1.36)$ \\
T-SCORE SPINE & $-0.49(1.9)$ & & $-0.61(1.26)$ & & $-0.24(1.34)$ \\
T-SCORE NECK & $-0.95(1.53)$ & & $-1.29(1.41)$ & & $-1.53(1.16)$ \\
T-SCORE HIP & $-1.02(1.58)$ & & $-1.38(1.58)$ & & $-1.42(1.33)$ \\
TOTAL & & & & & \\
CALCIUM SUPP & 29 & $20(62.5 \%)$ & 26 & 27 & 22 \\
& $(60.42 \%)$ & & $(72.22 \%)$ & $(72.97 \%)$ & $(68.75 \%)$ \\
VIT D SUPP & 46 & $2(6.25 \%)$ & 35 & $36(97.3 \%)$ & $32(100 \%)$ \\
& $(95.83 \%)$ & & $(97.22 \%)$ & & \\
BIPHOSPHONATE & $4(8.33 \%)$ & $5(15.62 \%)$ & $3(8.33 \%)$ & $5(13.51 \%)$ & $6(18.75 \%)$ \\
DENOSUMAB & $7(14.58 \%)$ & $7(21.87 \%)$ & $7(19.44 \%)$ & $7(18.91 \%)$ & $7(21.87 \%)$ \\
\hline
\end{tabular}

On multivariate analysis an inverse relationship between vitamin $D$ and CTX levels was detected $(p \leq 0.05)$. DEXA hip measures tend to become stabilized after Bisphosphonate treatment.

Conclusion: On our cohort, bone resorption biomarkers decrease after Vitamin D restoring. Antiresorptive therapy in high risk patients stopped bone loss, especially in hip. After two years follow up, with the treatment algorithm applied, fracture incidence was lower than other series published.

\section{REFERENCE}

[1] *J Musculoskelet Neuronal Interact 2011: 11(3):257-265

Disclosure of Interests: None declared

DOI: 10.1136/annrheumdis-2019-eular.5953

\section{AB0842 SARCOPENIA IN ALCOHOLIC WOMEN}

Kayo Masuko $^{1,2}$, Chie Iwahara $^{3}$, Seiji Sakate ${ }^{4}$, Yumiko Tanaka ${ }^{5}$, Shigemi Kamiya ${ }^{3}$, Yuki Mizukami ${ }^{4}$ ' Sanno Medical Center, Tokyo, Japan; ${ }^{2}$ International University of Health and Welfare, Tokyo, Japan; ${ }^{3}$ National Hospital Organization Kurihama Medical and Addiction Center, Kanagawa, Japan; ${ }^{4}$ Sagami Women's University, Kanagawa, Japan; ${ }^{5}$ National Hospital Organization Disaster Medical Center, Tokyo, Japan

Background: Recent statistics indicated an accumulating number of patients with alcohol dependency in Japan. In particular, there had been a considerable increase in the number of alcoholic women, reaching up to 130,000 patients. Because alcoholic women often have insufficient dietary intake and physical inactivity, they may be at risk for low bone mineral density and decreased muscle power. However, these points may not be widely recognized, and the current program for the rehabilitation of alcoholism may not be sufficient to address this issue.

Objectives: To assess the risk for osteoporosis and sarcopenia in alco holic women from a nutritional viewpoint

Methods: Thirty-two women (mean age: $42.9 \pm 7.49$ years) who were admitted to the Alcoholics Rehabilitation Program (ARP) for alcoholism, which was diagnosed according to International Classification of Diseases (ICD)-10, were enrolled in the study. The patients were subjected to self answered questionnaire, nutritional assessment by expert dietitians, and measurement of body composition and grip strength.

Results: Of the 32 patients, $14(44.0 \%)$ had a history of eating disorder, mostly anorexia. All 32 patients had elevated levels of transaminases at the time of admission. History of bone fracture was present in eight of the $32(25.0 \%)$ patients; among them, at least three $(9.4 \%)$ cases were considered to be due to a fragility fracture. The mean body mass index (BMI) was $20.4 \mathrm{~kg} / \mathrm{m} 2 ; 10$ (31.3\%) patients had $\mathrm{BMI}<18$. The average energy intake was low at $1,474.5 \pm 324.3 \mathrm{kcal}$. Twenty-one $(65.6 \%)$ patients were taking dietary calcium of $<650 \mathrm{mg} /$ day, which is the leve recommended for adult women. The mean grip strength was $23.8 \pm 6.5$ $\mathrm{kg}$, and $8(25 \%)$ patients had grip strength of only $<18 \mathrm{~kg}$, which is the definition of sarcopenia in the Asian elderly.

Conclusion: Young to middle-aged alcoholic women should be treated as having high risks for osteoporosis and sarcopenia. ARP should include multidisciplinary assessment and interventions to prevent future locomotive disabilities.

Disclosure of Interests: None declared

DOI: 10.1136/annrheumdis-2019-eular.5262

\section{AB0843 HYPOVITAMINOSIS D IN A MARFAN POPULATION}

Daniela Melchiorre $^{1}$, Elisa Pratelli ${ }^{2}$, Renato Colombai ${ }^{3}$, Marco Matucci-Cerinic ${ }^{1}$, Guglielmina Pepe ${ }^{1} .{ }^{1}$ University of Florence, Florence, Italy, ${ }^{2} \mathrm{AOU}$ Careggi Hospital, Florence, Italy, ${ }^{3}$ Department of Public Health, Pontedera, Italy

Background: Marfan syndrome is an autosomal dominant disorder of connective tissue caused by mutations in FBN1 gene on the long arm of chromosome 15. Information is often lacking regarding an increased risk of fractures and its management and prevention in patients with Marfan syndrome. In these patients reduced bone mineral density was rarely reported. A pivotal role in bone mineralization is played by Vitamin D.

Objectives: This study evaluates whether the reduction of the values of Vitamin $D$ is present in Marfan patients.

Methods: 60 patients (pts) (28 M/32 F; age 15-75 mean age 46,2) with Marfan syndrome were studied. The patients were followed from the clinical and research regional Marfan Center in Florence, Italy. All pts met new Ghent criteria that identified ectopia lentis, thoracic aorta dilatation with $\mathrm{Z}$ score $=$ or $>2$ and a large group of systemic clinical features represented by cardiovascular, musculoskeletal, central nervous system (dural ectasia) pulmonary, cutaneous and ocular clinical manifestations (systemic features) reaching a score $=$ or $>7$ as major clinical criterion. Familiarity and the detection of a gene mutation (in MFS FBN1 gene dis plays a mutation in about $90 \%$ of patients) are also considered criteria necessary for Marfan diagnosis.

Results: $11 / 60$ pts (18,3\%) (5M/6F age 15-75 mean age 44,9) showed reduced values of Vitamin D. 6/11 pts (45,4\%) (3M/3F age $15-56$, mean age 34,1 ) showed very poor Vitamin D values (range $8.7 \mathrm{ng} / \mathrm{ml}-13,17$ $\mathrm{ng} / \mathrm{ml})$.

Conclusion: Our results suggests that Vitamin D may play an important role in bone metabolism in Marfan patients. These results need confirmation since further data are missing in literature.

\section{REFERENCES}

[1] Trifirò G, Marelli S, Viecca M, Mora S, Pini A. Areal bone mineral density in children and adolescents with Marfan syndrome: evidence of an evolving problem.

[2] Bone. 2015 Apr;73:176-80. doi: 10.1016/j.bone.2014.12.006. Epub 2014 Dec 13.

Disclosure of Interests: Daniela Melchiorre: None declared, Elisa Pratelli: None declared, Renato Colombai: None declared, Marco Matucci-Cerinic Grant/research support from: Actelion, MSD, Pfizer, BMS, Chemomab, Sanipedia, Speakers bureau: Actelion, BMS; MSD, Janssen, Guglielmina Pepe: None declared

DOI: 10.1136/annrheumdis-2019-eular.8229 